\title{
Alunos com altas habilidades/superdotação: como se veem e como são vistos por seus pais e professores
}

\section{Highly skilled/gifted students: how they see themselves and how they are seen by their parents and teachers}

\author{
Lurian Dionizio Mendonça* \\ Olga Maria Piazentin Rolim Rodrigues* \\ Vera Lucia Messias Fialho Capellini*
}

\begin{abstract}
RESUMO
O presente estudo buscou descrever como alunos com altas habilidades/ superdotação (AH/SD), se veem e são vistos por seus pais e professores por meio dos seus relatos, com o objetivo de prover um conjunto de informações que subsidiariam a implementação de práticas educacionais mais favoráveis ao desenvolvimento das habilidades desses alunos. Participaram da pesquisa 11 alunos com AH/SD, seus pais e professoras. O método utilizado foi a entrevista semiestruturada gravada em áudio e transcrita para análise dos dados. Como resultados, observou-se que os alunos conhecem pouco sobre suas potencialidades, uma vez que seus conhecimentos em relação às possibilidades de estudo se reduzem às disciplinas do currículo escolar. Ouvindo os pais constatou-se que eles identificavam que seu filho era diferente, mas não tinham conhecimento suficiente para saber como ajudálos. Quanto aos professores observou-se que sabem pouco sobre o tema e, especialmente, como identificá-los e o que oferecer na sala de aula regular. Com base nos dados obtidos, conclui-se que, para os alunos, um primeiro passo seria o oferecimento de enriquecimento curricular, ampliando,
\end{abstract}

* Universidade Estadual Paulista Júlio de Mesquita Filho. Programa de Pós-Graduação de Pós-Graduação em Psicologia do Desenvolvimento e Aprendizagem. E-mail: luriandmendonca@ gmail.com - https://orcid.org/0000-0003-1734-6676 E-mail: olgarolim@fc.unesp.br - https://orcid. org/0000-0002-5332-256X E-mail: vera.capellini@unesp.br - https://orcid.org/0000-0002-9184-8319 
assim, seus horizontes e escolhas. Para os pais é necessário que recebam informações e orientações, podendo se transformar em bons parceiros, colaborando no desenvolvimento das potencialidades de seus filhos. Para os professores é urgente que tenham formação continuada sobre o tema para que possam colaborar efetivamente no desenvolvimento destes alunos.

Palavras-chave: Altas Habilidades. Superdotação. Pais. Professores. Educação Especial.

\begin{abstract}
The present study sought to describe how students with high skills/giftedness (HA/GD), see themselves and are seen by their parents and teachers through their reports, with the aim of providing a set of information that would support the implementation of educational practices more favorable to the development of the skills of these students. Eleven students with HA/ GD, their parents and teachers participated in the research. The method used was the semi-structured interview recorded in audio and transcribed for data analysis. As a result, it was observed that students know little about their potential, since their knowledge regarding the possibilities of study is reduced to the subjects of the school curriculum. Listening to the parents, it was found that they identified that their children was different, but did not have enough knowledge to know how to help them. As for teachers, it was observed that they know little about the topic and, especially, how to identify them and what to offer in the regular classroom. Based on the data obtained, it is concluded that, for students, a first step would be to offer curricular enrichment, thus expanding their horizons and choices. For parents it is necessary that they receive information and guidance, being able to become good partners, collaborating in the development of their children's potential. For teachers, it is urgent that they have continued training on the topic so that they can collaborate effectively in the development of these students.
\end{abstract}

Keywords: High Abilities. Giftedness. Parents. Teachers. Special Education.

\title{
Introdução
}

Existem muitas teorias e mitos sobre quem são os indivíduos com altas habilidades/superdotação (AH/SD). Alencar (2001, p. 119) trouxe algumas dessas diferentes percepções sobre estas pessoas e o que essa terminologia sugere: 
[...] para algumas, o superdotado seria o gênio, aquele indivíduo que realmente apresenta um desempenho extraordinário e ímpar em uma determinada área do saber e do conhecimento; para outros seria um jovem inventor que surpreende pelo registro de uma nova patente; para outros ainda, seria aquele aluno que sistematicamente se situa entre os primeiros da classe durante toda a sua formação acadêmica, ou a criança precoce, que aprende a ler sem ajuda e que surpreende seus pais por seus interesses e indagações próprias de uma criança mais velha. $\mathrm{O}$ termo superdotado sugere ainda, a presença de um talento, seja na área musical, literária ou de artes plásticas. $\mathrm{O}$ denominador comum em todas as diversas conotações do termo é a presença, pois, de um notável desempenho ou de habilidades ou aptidões superiores.

A atual Política Nacional de Educação Especial, na Perspectiva da Educação Inclusiva (BRASIL, 2008), definiu que os alunos com AH/SD são aqueles que demonstram potencial elevado em qualquer uma das seguintes áreas, isoladas ou combinadas: intelectual, acadêmica, liderança, psicomotricidade e artes. Apresentam, também, grande criatividade, envolvimento na aprendizagem e na realização de tarefas em áreas de seu interesse.

Tannembaum (1991) alertou que só se pode considerar um indivíduo com AH/SD se ele apresentar ou estiver exposto a alguns dos seguintes fatores: (a) um intelecto geral superior; (b) aptidões especiais em algum domínio ou área do conhecimento; (c) um conjunto de traços não intelectivos (como motivação intrínseca, independência, coragem para correr riscos, autoconceito positivo, etc.); (d) um ambiente desafiador e facilitador, que ajude a criança a se desenvolver num clima de afeto, desafio e encorajamento e, (e) sorte em momentos decisivos da vida. $\mathrm{O}$ autor acrescentou que muito do sucesso futuro do indivíduo provêm de fatores não preditivos, de se estar no local certo no momento adequado, ou de estar com a mente preparada para reconhecer uma experiência única ou rara. Para ele, ainda, estes elementos interagem de diferentes formas em cada domínio de talento e não podem ser considerados isoladamente.

Em relação às características dos alunos com AH/SD, Pérez (2002, s/p.) afirmou que:

[...] embora não apresente um perfil padronizado, geralmente possui diferenças qualitativas e quantitativas muito significativas em relação a seus pares, no que tange a interesses; motivação; criatividade; estilo e estratégias de aprendizagem; tolerância; senso de humor; auto-regulação; tratamento, interconexão e utilização das informações, entre outras. Estas 
diferenças geram necessidades educativas específicas que, quando não atendidas, costumam provocar a sua exclusão e/ou rejeição, seja por parte dos educadores, dos colegas ou inclusive por parte da sua própria família.

Zaia, Nakano e Peixoto (2018), apontam que as características encontradas nas pessoas com $\mathrm{AH} / \mathrm{SD}$ podem ser cognitivas ou não cognitivas, sendo as últimas, os comportamentos sociais, atributos e habilidades, tais como, motivação, persistência, empatia, perfeccionismo, preocupações éticas, responsabilidade, curiosidade e senso de humor, entre outros. Deste modo, as características cognitivas e não cognitivas devem ser consideradas com o mesmo nível de importância na identificação e desenvolvimento desses indivíduos.

Na visão de Winner (1998) as crianças com AH/SD manifestam o potencial em sua área de domínio em uma idade anterior à esperada e apresentam uma facilidade maior em aprender do que as demais. Essa autora salientou que essas crianças necessitam de pouco auxílio por parte dos adultos e são capazes de fazer descobertas por si só, encontrando novas maneiras para resolver problemas de sua área de interesse. Demonstram, ainda, criatividade, e um interesse intenso e obsessivo por dominar sua área de talento, que ela denominou "fúria por dominar". Gama (2006, p. 83) definiu esta dedicação obstinada à tarefa como:

[...] uma dedicação desmedida, que não se vê em crianças ou jovens da mesma idade. É uma capacidade de concentração por períodos de tempo muito superiores ao que se espera de alunos nas mesmas condições e de igual idade. É a habilidade de focalizar agudamente em alguma atividade, seja uma tarefa, uma aula, o desenvolvimento de um projeto ou outra qualquer.

Quando uma criança é identificada com $\mathrm{AH} / \mathrm{SD}$, ela passa a ser considerada como especial pela família, que passa a se configurar de maneira diferente, de modo a focalizar toda sua energia nessa criança. Winner (1998) observou dois tipos de envolvimento das famílias com seus filhos superdotados: um integrante da família ou ambos dispendem uma grande quantidade de tempo estimulando e ensinando a criança, ou fazem sacrifícios para que ela receba treinamento de alto nível dos melhores professores disponíveis. A autora colocou que, nessas duas situações, como a vida familiar é totalmente organizada em torno das necessidades dessa criança, faz com que os pais canalizem seus interesses no talento do filho, transferindo as esperanças de um futuro positivo para essa criança. Porém, isso pode ser prejudicial, uma vez que, ela pode se sentir sobrecarregada 
e até mesmo desmotivada, tendo seus próprios sonhos e expectativas anulados diante dos sonhos de seus pais. Landau (2002, p. 155) ainda complementou:

\begin{abstract}
Muitas vezes, a superambição de uma criança está espelhada na superambição do pai ou da mãe, que visa tão somente aos fins (resultados) e não aos meios (capacidades e ações). Por outro lado, há pais que se embevecem com o sucesso dos filhos. Sentindo o reconhecimento dos outros refletido sobre si próprio, eles chegam a causar embaraços às crianças, até mesmo afastando-as das outras, quando se gabam das vitórias delas. Algumas crianças superdotadas ficam magoadas, porque imaginam que são amadas apenas pelo talento que demonstram, a ponto de apresentar fracassos escolares. Em casos extremos, os pais as exploram, forçando-as a exaustivos exercícios de suas aptidões e negligenciando-lhes o desenvolvimento global, com finalidade de exibir-se.
\end{abstract}

A família, portanto, deve estimular, mas não criar expectativas muito altas em relação à criança. Por isso, é de suma importância que os pais recebam orientações de como devem participar efetivamente no desenvolvimento do talento de seu filho, de forma a estimulá-lo, mas não transferindo questões pessoais e sem criar expectativas irreais.

Deve-se levar em conta que, estimular os filhos, não significa dizer que os pais sejam capazes de "criar" o dom em seus filhos, pois essa visão contradiz a literatura no que se refere aos determinantes relativos à hereditariedade e ao ambiente (FERNANDES, 2014). Landau (2002) explicou que a inteligência vai sendo formada com o passar dos anos, tanto que o quociente de inteligência (QI) não permanece estável ao longo da vida e, ainda ressalta, que as mudanças ambientais que geralmente ocorrem na família, podem agir negativamente na inteligência. Dessa forma, o contrário também ocorre. No que diz respeito à dinâmica escolar, Azinheiro e Martins (2005) apontaram as preocupações mais enfrentadas pelos pais das crianças com $\mathrm{AH} / \mathrm{SD}$. Na área acadêmica os autores destacaram alguns fatores que podem interferir, tanto para o bom como para o desenvolvimento deficitário das altas habilidades da criança assim como da sua adaptação no contexto escolar: descumprimentos das tarefas escolares repetitivas; desmotivação diante de metodologias pedagógicas repetitivas; falta de cumprimento de regras estabelecidas causando indisciplina, por exemplo, as respostas aos professores e aos colegas e atitudes de liderança; desvalorização de certos aspectos como critério de avaliação (organização dos cadernos e frequente má caligrafia); comportamentos de inquietude e distração permanente. 
Outro ponto é o diálogo pais-escola, em especial a dificuldade dos pais comunicarem as características especiais da criança e o motivo de um atendimento diferenciado, assim como a forma como os pais colocam suas exigências à escola. Pais se preocupam, até mesmo, com o relacionamento entre seu filho e os colegas da escola e com seus professores quanto ao cumprimento de regras e limites. Alunos com AH/SD tendem a questionar com frequência e desafiar a autoridade do professor ou outros profissionais da escola, como a coordenação e direção. Além de experimentarem frustrações e reações emocionais negativas excessivas quando contrariados. Conflitos internos podem ocorrer em função do descompasso entre o desenvolvimento cognitivo que se processa em ritmo muito superior ao desenvolvimento físico e emocional. Azinheiro e Martins (2005), alertaram, também, que pode ocorrer o isolamento dos filhos e dificuldades nas relações entre os irmãos.

Sakaguti e Bolsanello (2013) investigaram os sentimentos, dificuldades e expectativas de 12 pais em relação aos filhos com $\mathrm{AH} / \mathrm{SD}$. Observaram que os pais: expressaram sentimentos de insegurança, medo, angústia, preocupação frente à educação e ao futuro de suas crianças, em contraponto com sentimentos de privilégio, felicidade e orgulho; tiveram pouco apoio da escola, mas ainda esperam por políticas públicas que valorizem as $\mathrm{AH} / \mathrm{SD}$; se preocupam com o desajustamento social e o sub-rendimento escolar; relataram a dificuldade de lidar com a curiosidade dos filhos que fazem muitos questionamentos e nem sempre conseguem responder; reclamaram da solidão de não poderem compartilhar com outros pais suas angústias e dúvidas. As autoras concluíram ressaltando a relevância de apoiar os pais e a família por meio de informações e orientações; equipar os pais com subsídios teóricos para poderem ajudar e lutar por seus filhos e, também, modificar o que a sociedade pensa a respeito das pessoas com $\mathrm{AH} / \mathrm{SD}$.

Fleith (2007b) assinalou que, em uma concepção distorcida sobre a educação de crianças com $\mathrm{AH} / \mathrm{SD}$, alguns gestores escolares sugeriram que a família procure uma escola que seja "adequada" para esse tipo de aluno, confirmando um posicionamento de que eles precisam ser tratados diferentes dos demais, em uma escola especializada que só atenda esse alunado, o que contraria toda a concepção de uma escola inclusiva. A autora enfatizou que a melhor escola para qualquer aluno deve ser acolhedora, ter flexibilidade para atender as necessidades educacionais específicas dos seus aprendizes, manterem diálogo com a família, ser aberta para aprender e propiciar oportunidades diferenciadas para atender todas as potencialidades. Características que toda escola deveria ter para atender todos os alunos com $\mathrm{AH} / \mathrm{SD}$ que por lá passarem.

Fontes $(2009$, p. 74$)$ ressaltou que "o professor deve respeitar as necessidades de seus alunos, oportunizando meios de aprendizagem, a partir de uma 
reflexão constante sobre sua prática e da busca de suporte no ensino especializado". Brandão (2012) defendeu que os professores do ensino regular devem se sensibilizar para a diferença e se prepararem para lidar com alunos com necessidades educacionais especiais, em contexto de sala de aula, mesmo não sendo especialistas. Isso vai de encontro com a proposta de uma escola inclusiva, para todos, não só para os alunos com AH/SD.

Dentre as principais características apresentadas pelos alunos com $\mathrm{AH} / \mathrm{SD}$, podemos citar o fato de serem questionadores e investigadores, o que geralmente acaba causando certo receio por parte dos professores que:

[...] muitas vezes expressam-se de maneira defensiva reprimindo ou ignorando os questionamentos dos alunos. Os alunos com altas habilidades, assim como outros educandos, acabam frustrando-se com o ensino e buscam outras alternativas muitas vezes inconvenientes ao professor (perturbando as aulas, "indisciplina"), enquanto outros acabam evadindo da escola (MATTEI, 2008, p. 81).

O professor, portanto, deve estimular a curiosidade, evitando críticas destrutivas, promover o acolhimento mantendo o contato físico, ouvindo e respondendo sem julgar, encorajando a individualidade, ajudando a estabelecer prioridades de tempo e energia e criando condições para a partilha (BRANDÃO, 2012). Em uma pesquisa realizada por Paludo, Loos-Sant'Ana e Sant'Ana-Loos (2013) eles buscaram compartilhar os resultados de uma pesquisa empírica acerca da constituição da identidade da pessoa com $\mathrm{AH} / \mathrm{SD}$. O grupo investigado por eles apresentou um autoconceito mediano, o que permitiu compreender que eles percebiam em si habilidades, capacidades e possibilidades em um nível desejável, mas que não se superestimavam face à sua condição de sujeito com AH/SD. Em relação à autoestima, que é a avaliação que o sujeito faz sobre em si próprio, foi considerada positiva pelos participantes. Os autores constataram que a amostra pesquisada apresentava alta capacidade de resiliência, eram capazes de possuir habilidades para superar vivências hostis e desenvolver melhorias em si mesmos. Por fim, concluíram, de modo geral, que ao manifestar o autoconceito e autoestima positivos, os sujeitos se percebiam como pessoas com muitos atributos e ainda os apreciavam.

Em um estudo realizado com adolescentes talentosos, Chagas e Fleith (2011) examinaram as características cognitivas, acadêmicas, afetivas e sociais e identificaram os fatores que favorecem ou dificultam o desenvolvimento de suas habilidades, a partir da percepção deles mesmos, de seus familiares 
e professores. Os resultados indicaram que as características cognitivas e acadêmicas mais reconhecidas foram: autodidatismo, facilidade para aprender e dedicação aos estudos. Entre as características afetivas e sociais, destacaramse: determinação, timidez e preferência pelo isolamento social. Os fatores promotores do desenvolvimento das habilidades mais frequentes foram: suporte familiar e atendimento em sala de recursos e a principal barreira identificada foi a dificuldade de acesso aos serviços especializados.

Camargo e Freitas (2013) analisaram as definições apresentadas por 24 alunos, de diferentes programas de enriquecimento curricular, sobre AH/SD. Observou-se, entre eles, o consenso de que as pessoas com AH/SD possuem um potencial superior em uma ou mais áreas do conhecimento. Apareceram nas falas o senso ético, a preocupação com o meio ambiente, o perfeccionismo, a facilidade para aprendizagem, confirmando o que a literatura já aponta (ALENCAR; FLEITH, 2001; CHAGAS; FLEITH, 2010). Ainda no estudo de Camargo e Freitas apareceram nas falas dos alunos a necessidade de mostrar que são iguais aos outros e que querem ser aceitos, apesar de apresentarem AH/SD. Alguns até negaram seus comportamentos/indicadores de $\mathrm{AH} / \mathrm{SD}$, buscando serem acolhidos pelo grupo, atitudes estas, que podem dificultar a identificação dos estudantes com $\mathrm{AH} / \mathrm{SD}$, mascarando o seu reconhecimento, impossibilitando que sejam oferecidas oportunidades educacionais e socioemocionais indispensáveis para o seu desenvolvimento. $\mathrm{O}$ estudo concluiu sobre a importância de ouvir os alunos para conhecer suas necessidades.

Assim sendo, acreditamos que saber o que pensam sobre si mesmos e como os pais veem o seu filho pode prover um conjunto de informações que subsidiariam o encaminhamento a um serviço de atendimento terapêutico, que os auxiliariam, com práticas educativas mais favoráveis ao desenvolvimento de suas habilidades. E, principalmente, conhecer como os professores lidam com essa questão auxiliaria na formação inicial de professores e na continuada, para os que estão atuando, que preenchessem as lacunas no conhecimento criando um ambiente favorável ao desenvolvimento desses alunos.

Dessa forma, o presente trabalho buscou descrever como alunos identificados com $\mathrm{AH} / \mathrm{SD}$, se veem e são vistos por seus pais e professores por meio do relato deles mesmos. Enquanto objetivos específicos têm-se: descrever o desempenho na escola a partir do relato do próprio aluno; descrever as características de desenvolvimento dos alunos identificados com AH/SD a partir do relato dos pais e, descrever a percepção do professor com relação às AH/SD. 


\section{Procedimentos metodológicos da pesquisa}

Neste estudo participaram 11 alunos, sendo sete meninos e três meninas, com idade entre sete e nove anos. Quanto ao ano escolar que frequentavam, um é do $1^{\circ}$ ano, três do $2^{\circ}$ ano, um do $3^{\circ}$ ano e seis do $4^{\circ}$ ano. Além de, 10 pais dos alunos, sendo seis mães e dois pais e, seis professoras da sala de aula regular dos referidos alunos, das quais, três eram responsáveis por um aluno com $\mathrm{AH} /$ $\mathrm{SD}$ do $1^{\circ}$ ano $\mathrm{A}, 2^{\circ}$ ano $\mathrm{C}$ e $3^{\circ}$ ano $\mathrm{B}$, uma professora por dois alunos com $\mathrm{AH} /$ $\mathrm{SD}$ do $2^{\circ}$ ano $\mathrm{A}$ e duas professoras por três alunos com $\mathrm{AH} / \mathrm{SD}$ no $4^{\circ}$ ano $\mathrm{A}$ e C. Um dos pais não aceitou participar da pesquisa mas autorizou a participação do seu filho ${ }^{1}$.

Os dados foram coletados nas dependências da escola, sendo ela estadual, que atende alunos dos anos iniciais do ensino fundamental, localizada em um bairro de periferia em uma cidade do interior do estado de São Paulo.

Para atender aos objetivos propostos nessa pesquisa, foram elaborados roteiros de entrevista específicos para os alunos, pais e professores e foi utilizado um gravador para o registro do áudio. O roteiro de entrevista para os alunos era composto por 15 questões, relacionadas às suas habilidades, interesses e características, como motivação, criatividade, entre outras. No roteiro de entrevista para os pais, havia 13 perguntas sobre o desenvolvimento, a personalidade e, ainda, sobre as características apresentadas por seus filhos. Já o roteiro de entrevista para os professores era formado por sete questões, sobre como identificam características de alunos com $\mathrm{AH} / \mathrm{SD}$, quais atividades que eles oferecem em sala de aula, se já encaminharam para algum serviço de atendimento, se recebem apoio do sistema escolar, entre outras.

O roteiro de entrevista com os alunos, pais e professores foi aplicado individualmente com cada um dos participantes, em horários previamente agendados, nas dependências da escola, sendo gravadas em áudio. As respostas foram transcritas e agrupadas em categorias para análise dos dados.

1 A pesquisa se utilizou de dados empíricos da dissertação de mestrado intitulada "Identificação de alunos com altas habilidades ou superdotação a partir de uma avaliação multimodal", aprovada pelo Comitê de Ética em Pesquisa (CEP) sob o CAAE nº 20046813.2.0000.5398 e foram cumpridos os preceitos éticos como a assinatura do Termo de Consentimento Livre e Esclarecido pelos pais e professores e o Termo de Assentimento Livre e Esclarecido pelas crianças. 


\section{Resultados e discussão}

\section{Percepção dos alunos}

A Tabela 1 apresenta uma descrição das entrevistas realizadas com os alunos.

TABELA 1 - DESCRIÇÃO DAS ENTREVISTAS COM OS ALUNOS

\begin{tabular}{|c|c|c|}
\hline Questões & $\mathbf{F}$ & $\%$ \\
\hline \multicolumn{3}{|l|}{ 1. Você acha que tem facilidade para aprender? } \\
\hline Sim. & 8 & 72,73 \\
\hline \multicolumn{3}{|l|}{ 2. Quais as suas maiores habilidades ou talento? E áreas de interesse? } \\
\hline $\begin{array}{l}\text { Habilidades: Citam disciplinas escolares (Matemática, História, Ciências e } \\
\text { L. Portuguesa). }\end{array}$ & 5 & 45,45 \\
\hline $\begin{array}{l}\text { Interesse: Citam disciplinas escolares (Artes, Ed. Física, Matemática, Ciências } \\
\text { e História). }\end{array}$ & 8 & 72,73 \\
\hline \multicolumn{3}{|l|}{ 3. E as maiores dificuldades? } \\
\hline Descreve as disciplinas escolares (História, Geografia e Matemática). & 7 & 63,64 \\
\hline \multicolumn{3}{|l|}{ 4. Que disciplina você mais gosta? E menos gosta? } \\
\hline Gostam: Matemática. & 4 & 36,36 \\
\hline Não gostam: L. Portuguesa. & 6 & 54,54 \\
\hline \multicolumn{3}{|l|}{ 5. O que você gostaria de estudar que não tem na escola? O que motiva você? } \\
\hline Gostaria de estudar: Biologia/Química/Geografia. & 3 & 27,26 \\
\hline O que motiva: Descreve as áreas (Matemática, Ed. Física e Química). & 6 & 54,54 \\
\hline \multicolumn{3}{|l|}{ 6. Você presta atenção na aula? Do que sua nota é resultado? Como estuda? } \\
\hline Sim. & 9 & 81,82 \\
\hline De prestar atenção. & 7 & 63,64 \\
\hline Estuda lendo. & 5 & 45,45 \\
\hline \multicolumn{3}{|l|}{ 7. Você prefere desenvolver atividade sozinho ou com amigos? De que idade? } \\
\hline Com colegas. & 6 & 54,54 \\
\hline Da idade dele. & 8 & 72,73 \\
\hline \multicolumn{3}{|l|}{ 8. Você se acha criativo? Como ela se expressa? } \\
\hline Sim. & 5 & 45,45 \\
\hline Pintando/desenhando. & 5 & 45,45 \\
\hline \multicolumn{3}{|l|}{ 9. Você se relaciona bem com a sua família? } \\
\hline Sim. & 9 & 81,82 \\
\hline
\end{tabular}

FONTE: Elaborada pelas autoras.

Observa-se que dos alunos entrevistados, a maioria (72,73\%) acredita que tem facilidade para aprender. Alencar (2001), Tannembaum (1991) e Winner 
(1998) descreveram que uma das características marcantes desses alunos é a manifestação de um intelecto geral superior, ou seja, uma facilidade maior em aprender quando comparado com os demais. Apesar de novos, já identificaram suas potencialidades.

As disciplinas escolares foram atribuídas por $45,45 \%$ como as suas maiores habilidades ou talentos e, $72,73 \%$ as apontaram como as maiores áreas de interesse. Contudo 63,64\% as consideraram, também, como suas maiores dificuldades. Para ilustrar estes dados $36,36 \%$ responderam que a disciplina de que mais gostam é Matemática e os demais apontaram as disciplinas de História, Ciências, Artes e Educação Física. 54,54\% disseram que a disciplina que menos gostam é Língua Portuguesa e os outros se dividiram em Matemática, História e Geografia. Dos entrevistados, 27,26\% relataram que gostariam de estudar outras disciplinas que não estão presentes no seu currículo escolar, tais como Química, Biologia e idiomas e 54,54\% se sentem motivados com algumas áreas como Informática e Matemática. Aqui observa-se que os alunos conhecem pouco sobre o que existe, suas áreas de interesse, até então, se reduzem às disciplinas do currículo escolar.

Entre os estudantes, $81,82 \%$ disseram que prestam atenção na aula e $63,64 \%$ acreditam que suas notas escolares são boas como resultado disso. Os alunos atribuem seu bom desempenho ao que é oferecido pelo professor. Rodrigues e Pereira (2004) analisando a que os alunos atribuem o sucesso que tem na escola encontraram que, os mesmos alunos, atribuem ao que o professor ensina. Ainda encontraram que os professores creditam o sucesso à capacidade inerente dos alunos que, segundo eles, aprendem sozinhos.

Quanto à forma que estudam 45,45\% relatam que é por meio da leitura, como pode ser observado na fala dos alunos "eu leio o tanto que for necessário" $\left(2^{\circ}\right.$ ano) ou "fico lendo várias vezes" ( $4^{\circ}$ ano). Provavelmente a forma mais sugerida pelos professores que caracteriza o comportamento de "estudar", outros $27,27 \%$ disseram que fazem exercícios escolares, $18,18 \%$ que prestam atenção na professora e $9,1 \%$ que estudam fazendo pesquisas. Na sala de aula $54,54 \%$ dos entrevistados preferem desenvolver atividades em grupos, com os colegas. Deles, $72,73 \%$ preferem ter amigos da mesma idade. Camargo e Freitas (2013) encontraram dados semelhantes quando entrevistaram alunos com AH/SD que relataram valorizar a companhia de amigos. Todavia, outros autores levantam que há uma preferência pelo trabalho individual (CUPERTINO, 2008; FLEITH, 2007a). A diferença dos dados pode se dever à idade dos alunos entrevistados.

Respondendo à questão sobre criatividade, $45,45 \%$ dos alunos se consideram criativos, mas somente em atividades de pintura e desenho. Aqui levanta-se a hipótese de que as oportunidades de expressão da criatividade em alunos dos 
anos iniciais do ensino fundamental sejam por meio desse tipo de atividade, sem o desenvolvimento de atividades-problema que possibilitam o aparecimento de outras formas de criatividade para a solução de problemas. Virgolim, Fleith e Neves-Pereira (1999, p. 19) afirmaram que, "quem define o que é ou não criativo é o contexto cultural de cada povo, seus especialistas, as pessoas possuidoras e construtoras do conhecimento, das artes, da ciência, dos costumes". Em contrapartida, o fato deles não se perceberem como criativos pode ser explicado, porque esse potencial ainda tem sido pouco estimulado no contexto escolar (GONÇALVES; FLEITH; LIBÓRIO, 2011). Para Virgolim, Freitas e Neves-Pereira (1999, p. 28):

[...] a criatividade é um recurso humano natural que tem sido severamente inibido por obstáculos de natureza emocional e social e por um sistema de ensino que tende a subestimar as capacidades criativas do aluno e a reduzi-las abaixo do nível das suas reais possibilidades. O ensino tem subestimado o potencial criativo de seus alunos por estar ainda fortemente vinculado a um modelo cognitivo que não reconhece o pensamento criativo como parte de sua estrutura.

Com relação à convivência familiar, $81,82 \%$ dos alunos responderam que se relacionam bem com a família. O restante justificou que brigam com os irmãos ou com os pais, como pode ser observado na fala de uma aluna "mais ou menos, só converso um pouco, porque minha mãe e meu pai trabalham e estão cansados" ( $1^{\circ}$ ano).

Camargo e Freitas (2013), afirmaram que reconhecer os estudantes com $\mathrm{AH} / \mathrm{SD}$, a partir de como eles se veem, pode auxiliar na organização dos diferentes espaços educacionais frequentados por eles, de modo a oferecer atividades desafiadoras e poder entendê-los melhor, visando a qualificação das oportunidades educacionais, apreciando a singularidade de cada um e oferecendo novas oportunidades de desenvolvimento.

\section{Percepção da família}

Em relação às entrevistas feitas com as famílias dos alunos identificados com $\mathrm{AH} / \mathrm{SD}$, somente os pais de um aluno não respondeu ao roteiro de entrevista, sendo assim, as respostas se referem a 10 pais. A Tabela 2 mostra uma descrição das respostas dos pais. 


\section{TABELA 2 - DESCRIÇÃO DAS ENTREVISTAS COM A FAMÍLIA}

\begin{tabular}{|c|c|c|}
\hline Questões & $\mathbf{F}$ & $\%$ \\
\hline \multicolumn{3}{|l|}{ 1. Como foi o desenvolvimento do seu filho na primeira infância? } \\
\hline \\
\hline $\begin{array}{l}\text { Personalidade forte, bravo às vezes, gosta de mandar em todo mundo, nervoso, } \\
\text { sem paciência. }\end{array}$ & 3 & 30 \\
\hline \multicolumn{3}{|l|}{$\begin{array}{l}\text { 3. A escola chamou sua atenção sobre alguma habilidade ou precocidade } \\
\text { do seu filho? }\end{array}$} \\
\hline Não. & 6 & 60 \\
\hline \multicolumn{3}{|l|}{$\begin{array}{l}\text { 4. O filho de vocês tem alguma habilidade que se destaca de outras filhos/ } \\
\text { crianças? }\end{array}$} \\
\hline $\begin{array}{l}\text { Curiosidade em aprender as coisas, questionador, facilidade para aprender, } \\
\text { bem inteligente. }\end{array}$ & 6 & 60 \\
\hline \multicolumn{3}{|l|}{ 5. Quais atividades ele realiza fora da escola? } \\
\hline $\begin{array}{l}\text { Nenhuma (só brincar, assistir TV, jogar vídeo game, ler, ir à escola, e mexer } \\
\text { no computador). }\end{array}$ & 6 & 60 \\
\hline \multicolumn{3}{|l|}{ 6. De que maneira vocês estimulam seu filho? } \\
\hline $\begin{array}{l}\text { Mostrando a importância de estudar, ir à escola, ao curso de inglês, colocando } \\
\text { um objetivo. }\end{array}$ & 6 & 60 \\
\hline \multicolumn{3}{|l|}{ 7. Vocês acreditam que seu filho tem facilidade de aprender? Como? } \\
\hline Sim. & 10 & 100 \\
\hline $\begin{array}{l}\text { Entende as coisas facilmente (não precisa falar mais de uma vez, questiona } \\
\text { bastante). }\end{array}$ & 7 & 70 \\
\hline \multicolumn{3}{|l|}{ 8. Quanto tempo seu filho passa em uma atividade? } \\
\hline $\begin{array}{l}\text { Bastante tempo se for algo que gostam, não para até conseguir acertar o que } \\
\text { está fazendo. }\end{array}$ & 8 & 80 \\
\hline \multicolumn{3}{|l|}{ 9. O que o seu filho mais gosta de fazer em seu tempo livre? } \\
\hline Brincar. & 4 & 40 \\
\hline Ficar no computador. & 4 & 40 \\
\hline \multicolumn{3}{|l|}{ 10. Seu filho prefere desenvolver atividades individualmente ou em grupo? } \\
\hline Individual. & 4 & 40 \\
\hline \multicolumn{3}{|l|}{$\begin{array}{l}\text { 11. Descrevam um fato ocorrido com seu filho que tenha chamado atenção } \\
\text { de vocês. }\end{array}$} \\
\hline \multicolumn{3}{|l|}{$\begin{array}{l}\text { 12. Como é o relacionamento do seu filho com a família? Tem facilidade } \\
\text { para fazer amigos? }\end{array}$} \\
\hline Bom, tranquilo. & 8 & 80 \\
\hline Tem, bastante. & 7 & 70 \\
\hline
\end{tabular}

FONTE: Elaborada pelas autoras. 
Quanto ao desenvolvimento de seus filhos $40 \%$ dos pais responderam que eles começaram a falar antes da idade normal e aprenderam tudo muito cedo. Em relação à personalidade $30 \%$ apontaram que eles têm personalidade forte, que às vezes são bravos, gostam de mandar em todo mundo, ficam nervosos e sem paciência. Ainda que presente em menos da metade dos participantes, são características comuns aos alunos com AH/SD (BRASIL, 2002) o fato de se desenvolverem muito cedo, de apresentarem uma maior desenvoltura no trabalho individual, de terem uma tendência em dominar as pessoas, de recusarem a aceitação de autoridades, características estas, que os pais sinalizaram como personalidade forte e, ainda, a curiosidade e os questionamentos.

Dos pais, $60 \%$ afirmaram que a escola nunca apontou alguma habilidade e/ou precocidade de seu filho. Maia-Pinto e Fleith (2002) enfatizaram que a identificação de crianças com AH/SD pode ser feita pelos pais, a partir da percepção do desenvolvimento de seus filhos, que costuma ser diferente dos demais, mas que ela acaba sendo identificada pela escola, pelos professores que acompanham com frequência o processo de aprendizagem dessas crianças e que, teoricamente teriam mais condições de encaminhá-los para outros serviços e, oferecer atividades diferenciadas a eles. No caso deste estudo, considerando a localização da escola, em um conjunto habitacional popular, há uma chance de os pais não estarem preparados para identificar as $\mathrm{AH} / \mathrm{SD}$ de seus filhos por desconhecê-las. Porém, o mais grave, é mostrar que a escola não está atenta às necessidades de seus alunos.

Deles, $60 \%$ afirmaram que seus filhos são mais curiosos e que eles questionam muito, diferentemente das outras crianças e/ou filhos. Chagas e Fleith (2011) relataram que uma das características presentes no repertório de crianças com $\mathrm{AH} / \mathrm{SD}$ é a curiosidade e, consequentemente, o comportamento inquisidor de quem quer aprender sobre muitas coisas. Todavia, nem sempre os pais estão preparados ou têm todas as informações que seus filhos solicitam. Sakaguti e Bolsanello (2013) encontraram que pais relataram angústia em não conseguir atender todos os questionamentos de seus filhos.

Deles, $60 \%$ disseram que eles não praticavam nenhuma atividade fora da escola e, ainda, relataram que estimulam seus filhos incentivando-os a estudar, mostrando a importância da escola. Ainda, 100\% acreditam que seus filhos têm facilidade para aprender e $70 \%$ disseram que é porque eles entendem as coisas facilmente, não é preciso falar mais de uma vez, como pode ser verificado na fala de uma das mães "[...] ela aprende bem fácil as coisas. Você fala com ela uma vez só e ela entende as coisas" ( $1^{\circ}$ ano). Dos pais, $80 \%$ falaram que seus filhos costumam passar bastante tempo em uma atividade, desde que eles gostem, $40 \%$ disseram que o que eles mais gostam de fazer no tempo livre é brincar, outros $40 \%$ apontaram ficar no computador e relataram que seus filhos preferem fazer 
atividades individualmente. Chagas e Fleith (2011), Gama (2006) e Winner (1998) apontaram que crianças com facilidade para aprender costumam passar muito tempo em uma mesma atividade, apresentando dedicação e concentração em tarefas desafiantes e do seu agrado por longos períodos.

Ao pedir para que descrevessem um fato ocorrido com seus filhos que tenha chamado a atenção da família, $40 \%$ relataram a compreensão, a percepção e atenção que eles têm, conforme a fala de um pai

"o que mais me marca assim nele é a compreensão que ele tem sabe [...] do nada ele pega assim e fala: 'é assim que a vida é, é assim que tem que ser', ele compreende fatos de hoje em dia, que a gente não passou pra ele [...] ele compreende, ele é muito compreensivo" ( $4^{\circ}$ ano).

Quanto ao relacionamento com a família, $80 \%$ apontaram que é bom e tranquilo e $70 \%$ afirmaram que eles têm facilidade para fazer amigos.

Webb, Gore, Almeida e DeVries (2007) salientaram que a escola deveria promover troca de experiências entre pais de crianças com AH/SD. Desta forma, proporcionariam novas perspectivas sobre o entendimento dos comportamentos apresentados pelos filhos, bem como possibilitariam o desenvolvimento de estratégias para lidar com diferentes situações.

\section{Percepção dos professores}

As entrevistas foram realizadas com seis professoras dos alunos identificados com AH/SD. A Tabela 3 mostra que $83,33 \%$ dos professores reconheceram que alunos com AH/SD necessitam de um atendimento educacional especializado. Todavia, alguns relataram que, por serem mais inteligentes não precisam de ajuda, que eles conseguem tudo por si próprio. Contudo, o aluno com AH/SD faz parte do público-alvo da Educação Especial (BRASIL, 2008) e, por isso, tem direito a ter um atendimento educacional especializado. 


\section{TABELA 3 - DESCRIÇÃO DAS ENTREVISTAS COM OS PROFESSORES}

\begin{tabular}{|c|c|c|}
\hline Questões & $\mathbf{F}$ & $\%$ \\
\hline \multicolumn{3}{|l|}{ 1. Alunos com AH/SD necessitam de um atendimento educacional especializado? } \\
\hline Sim. & 5 & 83,33 \\
\hline \multicolumn{3}{|l|}{ 2. Quais atividades você tem oferecido a esses alunos? } \\
\hline $\begin{array}{l}\text { Elencam atividades (extras de acordo com a curiosidade, mais desafiadoras, } \\
\text { produção de texto, práticas de leitura, orientação para a pesquisa e direcionamento } \\
\text { de livros). } \\
\text { 3. Quais outras atividades você poderia oferecer? }\end{array}$ & 4 & 66,66 \\
\hline Complementação (uma atividade além do currículo). & 2 & 33,33 \\
\hline \multicolumn{3}{|l|}{$\begin{array}{l}\text { 4. O que, em sua sala de aula, poderia ser modificado para melhor atender esses } \\
\text { alunos? }\end{array}$} \\
\hline $\begin{array}{l}\text { Ter mais recursos (materiais de informática, jogos, ter acesso à pesquisa, mais } \\
\text { livros). }\end{array}$ & 3 & 50,00 \\
\hline \multicolumn{3}{|l|}{ 5. Já encaminhou algum desses alunos para outros serviços? } \\
\hline Não. & 3 & 50,00 \\
\hline Sem ser para esse projeto, não. & 3 & 50,00 \\
\hline \multicolumn{3}{|l|}{$\begin{array}{l}\text { 6. Espera receber ajuda de outros profissionais para um melhor atendimento? } \\
\text { Quais? }\end{array}$} \\
\hline Sim. & 6 & 100,00 \\
\hline $\begin{array}{l}\text { Alguém que possa aprimorar a habilidade do aluno, psicopedagogos, psicólogos, } \\
\text { pessoas que possam estar orientando. }\end{array}$ & 3 & 50,00 \\
\hline \multicolumn{3}{|l|}{ 7. Sabe onde procurar essa ajuda? } \\
\hline Não. & 3 & 50,00 \\
\hline
\end{tabular}

FONTE: Elaborada pelas autoras.

Rangni e Costa (2014), apontaram que acreditar que os alunos com $\mathrm{AH} / \mathrm{SD}$ são independentes e conseguem 'caminhar por si sós' é o mito mais perverso existente sobre essa população e que as próprias políticas públicas têm contribuído para a perpetuação desse mito, através de ações que privilegiam outras necessidades educacionais especiais, com destaque para as deficiências. Pérez e Freitas (2011, p. 111) ressaltaram que:

[...] a representação cultural deturpada leva a pensar que o aluno com AH/SD é uma pessoa rara, que não precisa de nada, que se autoeduca, que somente existe em classes privilegiadas, que só pode ser o aluno nota 10 na sala de aula e, principalmente, que não é um aluno com necessidades educacionais especiais, pois este termo é equivocadamente reservado aos alunos com deficiência. 
Das professoras entrevistadas, $66,66 \%$ elencaram atividades que têm oferecido, como atividades extras de acordo com a curiosidade do aluno, atividades de produção de texto, práticas de leitura e orientação para a pesquisa. Ainda, 33,33\% disseram que podem oferecer atividades de complementação e outros 33,33\% relataram atividades como produção de texto, jogos e no computador, uma das professoras, por exemplo, disse "Acho que mais escrita da parte deles, produção de texto, reconto" ( $2^{\circ}$ ano). Dessas professoras, $50 \%$ apontaram que na sua sala poderia ter mais recursos, materiais de informática, tecnologia e livros, para atender melhor esses alunos. Entretanto, autores têm encontrado em suas pesquisas que o que mais aparece como atividade extra é em relação à escrita, como produção de textos e prática de leitura, que já é algo muito trabalhado nas escolas (CALLAHAN; MOON; OH, 2017; FLEITH, 2007a; VIRGOLIM; FLEITH; NEVES-PEREIRA, 1999). Eles sugerem que a escola deveria oferecer, por exemplo, mais atividades de estimulação à criatividade, a resolução de problemas e à pesquisa.

Dos professores $50 \%$ disseram nunca ter encaminhado nenhum aluno com $\mathrm{AH} / \mathrm{SD}$ para outros serviços e o restante deles só encaminhou para um projeto de extensão que foi realizado na escola com o objetivo de identificar os alunos com AH/SD. Esta questão chama atenção e reforça o já apontado pelos pais. Eles não encaminham nenhum aluno para outros serviços ou atendimentos, mostrando que eles passam despercebidos na escola. Marques (2010) alerta que a identificação é imprescindível, sendo ela, o passo inicial no atendimento às suas necessidades. Rangni e Costa (2012, p. 211), reafirmaram que as crianças com AH/SD ainda não são identificadas e, consequentemente, atendidas em suas necessidades, ficando "à margem esperando serem vistas nas salas de aulas ou nos corredores de alguma instituição de educação de nosso país".

Todos (100\%) afirmaram que esperam receber ajuda de outros profissionais para atender melhor esses alunos, conforme relata uma das professoras "Seria importante que houvesse alguma orientação ou mesmo que houvesse um atendimento especializado que nos orientasse a como trabalhar com esses alunos" ( $4^{\circ}$ ano). Deles, $50 \%$ elencaram alguns profissionais que poderiam ser psicólogos e psicopedagogos, pessoas que possam estar orientando e aprimorando as habilidades desses alunos e, os demais relataram não saber onde procurar essa ajuda. Observa-se que esperam ajuda de profissionais de outras áreas, mas não incluíram a sua própria categoria, que pode ser um professor, que seja especializado e tenha experiência na área.

Bahiense e Rossetti (2014, p. 206), afirmaram que "crê-se ser necessária uma capacitação para que os profissionais que lidam com pessoas com AH/SD saibam identificar tais indivíduos e possam atuar da melhor forma com o objetivo de potencializar suas habilidades". 
Valle-Ribeiro e Barbosa (2014), ressaltaram que a formação do professor que vai atuar com os alunos com AH/SD é crucial e, por isso, esses profissionais devem possuir uma formação mais abrangente, devendo incluir a reformulação de conceitos errôneos até o desenvolvimento de características e habilidades para lidar e obter sucesso com essa população.

Pavão, Pavão e Negrini (2018), ainda complementam, dizendo que precisamos de profissionais mais criativos e atentos as necessidades de aprendizagem desses estudantes e, consequentemente ao investir na formação docente, novas práticas de ensino surgirão e poderão atender esses estudantes em suas reais necessidades.

\section{Considerações finais}

O presente estudo buscou descrever como alunos identificados com $\mathrm{AH} / \mathrm{SD}$, se veem e são vistos por seus pais e professores por meio de relatos. Os resultados indicaram que os dados obtidos com os alunos mostram como se veem e, considerando a idade e ano escolar deles, observa-se que conhecem pouco sobre suas potencialidades uma vez que seus conhecimentos sobre as possibilidades de estudo e aprimoramento são poucos, reduzindo-se a algumas das disciplinas do currículo escolar. Um primeiro passo no enriquecimento curricular ou um programa específico para alunos com AH/SD seria mostrar o que existe enquanto possibilidades de desenvolvimento, ampliando seus horizontes e escolhas.

Ouvindo os pais observou-se que até identificam que seu filho é diferente dos demais, mas não têm conhecimento suficiente para saber como ajudá-los. Mostrando-se necessário que esses pais recebam informações e orientações, podendo assim, se transformar em bons parceiros, colaborando no desenvolvimento das potencialidades de seus filhos. Porém, é preciso cuidar para que cobranças excessivas ou descontextualizadas não aconteçam visando evitar problemas emocionais que podem, no futuro, impedir que seus talentos sejam úteis a ele e à sociedade a que pertencem.

Quanto aos professores é urgente que sejam preparados para identificar alunos com $\mathrm{AH} / \mathrm{SD}$, encaminhá-los para serviços especializados, bem como para oferecer a eles, oportunidades de desenvolvimento proporcionando atividades que atendam suas necessidades também no contexto da classe comum. Identificar alunos com AH/SD ainda é um desafio que deve ser enfrentado pelo sistema escolar de forma que talentos não sejam desperdiçados e que a escola 
cumpra seu papel de formar integralmente todos os alunos. Não é necessário ter AH/SD para trabalhar com alunos com tais características, mas estar aberto ao novo e ao desafio.

Todavia, a população participante era pequena o que dificulta a generalização dos dados. Investigações com populações maiores podem confirmar ou, ainda, refutar os dados encontrados. Futuras pesquisas podem incluir adolescentes que já foram expostos a conhecimentos mais avançados e que, também, podem ter acesso a informações de outras fontes como a internet, por exemplo, o que pode ampliar o seu universo de conhecimentos.

\section{REFERÊNCIAS}

ALENCAR, Eunice S. Criatividade e educação de superdotados. Petrópolis: Vozes, 2001.

ALENCAR, Eunice S.; FLEITH, Denise S. Superdotados: determinantes, educação e ajustamento. São Paulo: EPU, 2001.

AZINHEIRO, Alexandra; MARTINS, Teresa. Intervenção com pais de crianças sobredotadas: reflexões e propostas. ANEIS - Associação Nacional para o Estudo e a Intervenção na Sobredotação. Braga, v. 6, p. 139-147, 2005.

BAHIENSE, Taisa R. S.; ROSSETTI, Claudia B. Altas Habilidades/Superdotação no Contexto Escolar: Percepções de Professores e Prática Docente. Revista Brasileira de Educação Especial. Marília, v. 20, n. 2, p. 195-208, 2014.

BRANDÃO, Carla P. R. A sobredotação como necessidade educativa especial: conhecer, identificar e intervir no ensino regular - perspectivas e práticas pedagógicas dos docentes do $1^{\circ}$ ciclo do ensino básico. 2012. 142 p. Dissertação (Mestrado em Ciências da Educação) - Escola Superior de Educação João de Deus, Lisboa, 2012.

BRASIL. Ministério da Educação e Cultura. Secretaria de Educação Especial. Projeto Escola Viva. Garantindo o acesso e permanência de todos os alunos na escola. Alunos com necessidades educacionais especiais. Brasília: MEC/SEESP, 2002.

BRASIL. Ministério da Educação. Secretaria de Educação Especial. Política Nacional de Educação Especial na Perspectiva da Educação Inclusiva. Brasília: MEC/ SEESP, 2008.

CALlaHAN, Carolyn M.; MOON, Tonya R.; OH, Sara. Describing the Status of Programs for the Gifted: A Call for Action. Journal for the Education of the Gifted, v. 40, n. 1, p. 20-49, 2017.

CAMARGO, Renata G; FREITAS, Soraia N. Altas habilidades/superdotação por estudantes com altas habilidades/superdotação. Revista Brasileira de altas habilidades/ superdotação (CONBRASD), v. 1, n. 1, p. 82-89, 2013. 
CHAGAS, Jane F.; FLEITH, Denise S. Habilidades, características pessoais, interesses e estilos de aprendizagem de adolescentes talentosos. Psico-USF, v. 15, n. 1, p. 93-102, 2010.

CHAGAS, Jane F.; FLEITH, Denise S. Perfil de Adolescentes Talentosos e Estratégias para o seu Desenvolvimento. Psicologia: Teoria e Pesquisa. Brasília, v. 27, n. 4, p. 385-392, 2011.

CUPERTINO, Christina M. B. (org.). Um olhar para as altas habilidades: construindo caminhos. São Paulo (Estado) Secretaria da Educação, CENP/CAPE. São Paulo: FDE, 2008.

FERNANDES, Tereza L. G. Capacidades silentes: Avaliação educacional diagnóstica de altas habilidades em alunos com surdez. 2014. 330 p. Tese (Doutorado em Educação) - Universidade Federal do Ceará, Fortaleza, CE, 2014.

FLEITH, Denise S. (org.). A construção de práticas educacionais para alunos com altas habilidades/superdotação. v. 1: orientação a professores. Brasília: Ministério da Educação, Secretaria de Educação Especial, 2007a.

FLEITH, Denise S. Desenvolvimento de talentos e altas habilidades: orientação a pais e professores. Porto Alegre: Artmed, 2007b.

FONTES, Rejane S. Ensino colaborativo: uma proposta de educação inclusiva. Araraquara, SP: Junqueira\&Marin, 2009.

GAMA, Maria Clara S. S. Educação de superdotados: teoria e prática. São Paulo: EPU, 2006.

GONÇALVES, Fernanda C.; FLEITH, Denise S.; LIBÓRIO, Ana Clara O. Criatividade em aula: percepção de alunos de dois estados brasileiros. Arquivos Brasileiros de Psicologia. Rio de Janeiro, n. 63, p. 1-110, 2011.

LANDAU, Erika. A Coragem de Ser Superdotado. São Paulo: Arte \& Ciência, 2002.

MAIA-PINTO, Renata R.; FLEITH, Denise S. Percepção de professores sobre alunos superdotados. Revista Estudos de Psicologia. Campinas, PUC, v. 19, n. 1, p. 78-90, 2002.

MARQUES, Clayton R. Levantamento de crianças com indicadores de altas habilidades em Jaboticabal/São Paulo. 2010. 167 f. Dissertação (Mestrado em Educação Especial). Universidade Federal de São Carlos. São Carlos, 2010.

MATTEI, Giovana. O professor e aluno com altas habilidades e superdotação: relações de saber e poder que permeiam o ensino. Revista Educação Especial. UFSM, v. 21, n. 31, p. 75-84, 2008.

PALUDO, Karina I.; LOOS-SANT'ANA, Helga; SANT'ANA-LOOS, René S. A identidade da pessoa com altas habilidades/superdotação sob a ótica do sistema teórico da afetividade ampliada. PsicoDom, ed. 12, 2013. Disponível em: https://www.researchgate. net/publication/327619777_A_IDENTIDADE_DA_PESSOA_COM_ALTAS HABILIDADESSUPERDOTĀCAO_SOB_A_OTICA_DO_SISTEMA_TEORICO_ DA_AFETIVIDADE_AMPLIADA. Acesso em: 20 out. 2019. 
PAVÃO, Ana Cláudia O.; PAVÃO, Sílvia M. O.; NEGRINI, Tatiane. Formação de professores para atenção aos alunos com Altas Habilidades/Superdotação. In: PAVÃO, Ana Cláudia O.; PAVÃO, Sílvia M. O.; NEGRINI, Tatiane. (orgs.). Atendimento educacional especializado para as altas habilidades/superdotação. Santa Maria: FACOSUFSM, 2018. p. 17-34.

PÉREZ, Susana G. P. B. Da transparência à consciência: uma evolução necessária para a inclusão do aluno com altas habilidades/superdotados. In: I Seminário de Inclusão de Pessoas com Altas Habilidades/Superdotados, II Seminário de Inclusão da Pessoa com Necessidades Especiais no Mercado de Trabalho, VI Seminário Capixaba de Educação Inclusiva, setembro, 2002, Vitória/ES. Anais... Vitória: UFES/Fórum Permanente de Educação Inclusiva/ABSD-ES/Fundação Ceciliano Abel de Almeida/FINDES-SENAI/ ES. 2002, CD-ROM.

PÉREZ, Susana G. P. B.; FREITAS, Soraia N. Encaminhamentos pedagógicos com alunos com Altas Habilidades/Superdotação na Educação Básica: o cenário brasileiro. Educar em Revista, n. 41, p. 109-124, 2011.

RANGNI, Rosemeire de A.; COSTA, Maria da Piedade R. Altas habilidades/superdotação e deficiência: reflexões sobre o duplo estigma. Educar em Revista, n. 53, p. 187-199, 2014.

RANGNI, Rosemeire de A.; COSTA, Maria da Piedade R. Indivíduos talentosos: o filme Gênio indomável como fonte de análise. Psicologia da Educação, v. 35, p. 197-213, 2012.

RODRIGUES, Olga M. P. R.; PEREIRA, Andreia A. Desempenho escolar: atribuições de causalidade diante do sucesso e do fracasso escolar. In: RODRIGUES; Olga M. P. R.; VALLE, Tania G. M.; ALMEIDA-VERDU, Ana Claudia M.; LOPES JUNIOR, Jair; CAVALCANTE, Maria Regina (orgs.). Psicologia do Desenvolvimento e Aprendizagem: investigações e análises. São Carlos/SP: RiMa Editora, p. 79-94, 2004.

SAKAGUTI, Paula M. Y.; BOLSANELLO, Maria Augusta. Filhos com Altas Habilidades/ Superdotação: sentimentos, dificuldades e expectativas dos pais. Revista Brasileira de altas habilidades/superdotação (CONBRASD), v. 1, n. 1, p. 99-101, 2013.

TANNEMBAUM, Abraham J. The social psychology of giftedness. In: COLANGELO, Nicholas; DAVIS, Gary A. (eds.). Handbook of gifted education. Boston: Allyn \& Bacon, 1991.

VALLE-RIBEIRO, Natália do; BARBOSA, Altemir J. G. Características da produção sobre professores de alunos com dotação e talento. Psicologia da Educação, v. 38, p. 101-112, 2014.

VIRGOLIM, Angela M. R.; FLEITH, Denise S.; NEVES-PEREIRA, Mônica S. Toc, toc... plim, plim!: Lidando com as emoções, brincando com o pensamento através da criatividade. Campinas: Papirus, 1999.

WEBB, James T.; GORE, Janet L.; AMEND, Edward R.; DEVRIES, Arlene R. A parent's guide to gifted children. Scottsdale: Great Potential Press, 2007. 
WINNER, Ellen. Crianças Superdotadas: mitos e realidades. Tradução de Sandra Costa. Porto Alegre: Artmed, 1998.

ZAIA, Priscila; NAKANO, Tatiana C.; PEIXOTO, Evandro M. Scale for Identification of Characteristics of Giftedness: Internal structure analysis. Estudos de psicologia, v. 35, n. 1, p. 39-51, 2018.

Texto recebido em $05 / 02 / 2020$.

Texto aprovado em 23/03/2020. 